\title{
Developing An Assessment Of Learning Process: The Importance Of Pre-Testing
}

Michelle Sheran, Ph.D., University of North Carolina at Greensboro, USA Jeffrey Sarbaum, Ph.D., University of North Carolina at Greensboro, USA

\begin{abstract}
Colleges and universities are increasingly being held accountable for assessing and reporting student learning. Recently there has been increased focus on using assessment to improve learning over time. In this paper we present a simple, step-by-step assessment process that will deliver meaningful results to achieve these ends. We emphasize the need to conduct controlled and consistent pre- and post-testing so that the impact of pedagogical changes can be effectively measured. We explain how we have utilized this process in our Principles of Microeconomics courses to assess learning objectives and show that absolute performance on the assessment of a learning objective is not always consistent with relative performance improvement. These results reinforce the need to use pre-testing to effectively assess learning and measure the impact of pedagogical changes over time.
\end{abstract}

Keywords: Assessment; Pre-testing; Learning Objectives; Microeconomics

\section{INTRODUCTION}

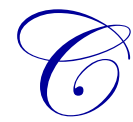

olleges and universities are increasingly being held accountable for assessing and reporting student learning. Accreditation agencies have been a big driver in this movement, but pressure is now also coming from the federal government, governing boards, and state legislatures (Myers, Nelson and Stratton 2009). There has additionally been a cultural shift in higher education towards assessment as a key element in student learning (Allen 2004). These changes have put pressure on departments and programs to develop assessment of learning processes to continually measure the extent to which they are meeting their learning objectives.

Almost two-thirds of economics departments have a formal assessment plan, according to a national survey of economics department chairs in the United States (Myers, Nelson and Stratton 2011). Yet, there is little in the economics literature that departments can use to guide these efforts (Myers, Nelson and Stratton 2011). Two recent papers offer systematic approaches to assessment in economics at the programmatic level (Myers, Nelson and Stratton 2009) and course level (Cariglia-Harris and Hill 2010). While these papers offer valuable assistance to departments seeking to develop and implement assessment of learning strategies, neither paper addresses the importance of pre-testing.

Pre-testing is essential for establishing a baseline. Without a measure of what students know at the beginning of a course or program, it is difficult to estimate the value added. Value-added approaches to assessment have become an important topic among education policymakers, researchers, and practitioners (Doran and Fleishchman 2005). In its 2006 report, A Test of Leadership: Charting the Future of U.S. Higher Education (U.S. Department of Education 2006), the Commission on the Future of Higher Education calls for colleges and universities to measure student achievement "on a "value-added" basis that takes into account students' academic baseline when assessing their results" (p. 4). According to the American Association of State Colleges and Universities in its 2006 report, Value-Added Assessment: Accountability's New Frontier, value-added assessment "speaks directly to the most important product of undergraduate education: the development of student knowledge and skills" (p. 3). 
The purpose of this paper is to present a six step guide for developing an effective, value-added assessment of learning system. We illustrate this process by describing how we applied it in our Principles of Microeconomics courses, though this same process can be utilized to assess another course or program. The contribution of this paper is that it proposes a simple assessment process that utilizes pre-testing to establish a baseline to which post-test results can be compared. We discuss the importance of pre-testing for generating meaningful and comparable data over time as well as for reducing the incentives faculty may have to alter the assessment system to produce desired results. We discuss how consistency in assessment is vital for generating data that can best help departments implement and track the success of quality improvement initiatives over time to enhance learning.

\section{STEP 1: DEFINE LEARNING OBJECTIVES}

Identifying the key content you want to deliver in a course is the first step in developing an assessment of learning process. Ideally, the faculty members responsible for teaching the course will participate in this step. Starting with a discussion of how the course is taught and what material is covered, these individuals should construct of list of critical topics which are common across sections and most essential to the course. In our Principles of Microeconomics courses, for example, we engaged in such a process from which the list of critical topics presented in Table 1 emerged.

Tab1e 1: Critical Topics

Marginal Analysis
Opportunity Cost and the PPF
Comparative Advantage
Supply and Demand
Elasticity
Government Intervention
Market Failures
Production/Cost Structure
Perfect Competition
Monopoly

Critical topics should then be grouped as appropriate into approximately 4 to 6 major areas of focus and formed into learning objectives. Learning objectives are broader than critical topics and communicate the overarching goals of a course utilizing action verbs. ${ }^{1}$ We formulated the learning objectives presented in Table 2 for our Principles of Microeconomics courses.

Table 2: Learning Objectives

LO1: Demonstrate how scarcity forces trade-offs, how every choice has an opportunity cost, and how different opportunity costs give rise to comparative advantages.

LO2: Apply knowledge of supply and demand, market equilibrium and elasticity to demonstrate how price allocates scarce resources.

LO3: Explain how markets reach efficient outcomes, why markets sometimes fail, and how government intervention can impact markets.

LO4: Describe a firm's production process and resulting cost structure and show how output decisions are made.

LO5: Distinguish between perfectly competitive and monopolistic markets and understand the implications of each on market efficiency.

Learning objectives can then be broken down into dimensions and even sub-dimensions if appropriate. Dimensions and sub-dimensions are narrower and more specific than learning objectives. As will be discussed in Step 2 below, the purpose of dimensions and sub-dimensions is to drill down a learning objective into more measurable units. Consider our first learning objective (LO1) in Principles of Microeconomics as an example. Within this learning objective, we defined the dimensions and sub-dimensions presented in Table 3.

\footnotetext{
${ }^{1}$ See Allen (2004) for a discussion of guidelines for writing effective learning objectives. 
Table 3: Dimensions and Sub-Dimensions

Learning Objective: LO1: Demonstrate how scarcity forces trade-offs, how every choice has an opportunity cost, and how different opportunity costs give rise to comparative advantages.

Dimension: LO1.1: Use a production possibility frontier to explain scarcity and opportunity cost.

Sub-Dimension: LO1.1.1: Use a PPF to identify efficient, inefficient and unattainable production points.

Sub-Dimension: LO1.1.2: Use a PPF to measure opportunity cost.

Dimension: LO1.2: Comprehend comparative advantage and the gains from specialization and trade.

Sub-Dimension: LO1.2.1: Compare the opportunity cost of two nations and determine comparative advantage.

Sub-Dimension: LO1.2.2: Identify a mutually beneficial terms of trade price.

Importantly, faculty responsible for delivering a course should review these learning objectives and approve them before moving forward in the development process. Getting faculty buy-in to any AOL process is difficult enough without having to contend with disagreement concerning the fundamental goals of a program or course. Faculty should agree with the list of learning objectives you have created. This is of critical importance because once the process is established it should not be changed. Changing the process will undermine the comparison of results over time.

\section{STEP 2: CREATE ASSESSMENT MEASURES}

Once learning objectives are well defined, you are ready to create measures to evaluate whether and the extent to which these objectives are being met. There are many ways to assess learning. ${ }^{2}$ The type of measure that is best for your course depends on class size, structure and content. In our Principles of Microeconomics courses, for example, class size is so large that exams and problem sets consist of only multiple choice questions. Thus, assessment measures for this class are in the form of multiple choice questions as well. In other classes, it may be appropriate to utilize an essay, research paper, presentation or project to assess learning objectives.

Assessment measures should target the sub-dimensions (or dimensions if no sub-dimensions exist) of learning objectives. This is the value of writing the sub-dimensions in the first place. Learning objectives are so broad that evaluating them with a single measure or with only a few measures can be difficult. Because dimensions and sub-dimensions are narrower and more specific, they are more easily assessed than the broader learning objectives to which they correspond. They lend themselves to the creation of focused measures.

Sometimes it is useful to create multiple measures per sub-dimension. These is especially true when using multiple choice questions since these questions generally gather less information than an essay, for example, and are easily graded. However, it is important not to construct too many measures per sub-dimension because the AOL system you develop has to manageable. In Tables 4 and 5 illustrate examples of measures in the form of multiple choice questions and an alternative essay question for our Principles of Microeconomics classes.

\section{STEP 3: CREATE A PRE- AND POST-TEST STRATEGY}

An effective assessment of learning process should utilize some form of pre-testing in addition to posttesting. The value of pre-testing cannot be stressed enough. Pre-testing creates a baseline to which post-test results can be compared. By comparing students' knowledge at two points in time we can better assess a course's value added. Moreover, pre-testing allows us to control for student quality, both across institutions and over time (American Association of State Colleges and Universities 2006). As will be discussed in Step 6, this is particularly important when using an assessment system to measure the impact of curricular/pedagogical changes made in an effort to "close the loop". Assessment programs that ignore pre-testing will have difficulty validating a continuous cycle of improvement process for which an assessment of learning process is designed.

\footnotetext{
${ }^{2}$ See Walstad (2001) for a discussion of assessment practices in economic education. 
Table 4: Multiple Choice Measures

Learning Objective

LO1: Demonstrate how scarcity forces trade-offs, how every choice has an opportunity cost, and how different opportunity costs give rise to comparative advantages.

Dimension

LO1.1: Use a production possibility frontier to explain scarcity and opportunity cost.

Sub-Dimension

LO1.1.1: Use a PPF to identify efficient, inefficient and unattainable production points.

\section{Measure \#1}

If a society is at a point inside its production possibilities frontier it implies that:

a. technology is improving.

b. all resources are used in production.

c. more output could be produced using the same resources.

d. goods are being produced with the optimal mixture of resources.

\section{Measure \#2}

The production possibilities frontier shows:

a. the products people want to have produced in a particular time period.

b. the types of products that will be able to be produced in the future

c. what an equitable distribution of products among citizens would be

d. combinations of products that can be produced with currently available resources.

Learning Objective

Table 5: Essay Question Measures

LO1: Demonstrate how scarcity forces trade-offs, how every choice has an opportunity cost, and how different opportunity costs give rise to comparative advantages.

Dimension

LO1.1: Use a production possibility frontier to explain scarcity and opportunity cost.

Sub-Dimension

LO1.1.1: Use a PPF to identify efficient, inefficient and unattainable production points.

Measure

Define and draw a PPF and identify production points that are attainable, unattainable, efficient and inefficient.

In our Principles of Microeconomics courses we pre-test our students on the second day of class. Our pretest consists of 20 multiple-choice questions, one for each sub-dimension of our learning objectives. We then embed these same 20 questions in the final exam for post-testing. It is important to try to establish post-test conditions that are similar to those of the pre-test. One potential criticism of our approach is that the incentives on an ungraded pretest are not the same as on a final exam, resulting in an overestimation of the gains. While this may be true, it is not of significant concern when measuring the impact of pedagogical changes implemented to enhancing learning. When addressing learning enhancement we want measures that provide clean information on year-over-year relative gains. Using consistent, repetitive pre- and post-testing is a simple way to generate data that is meaningfully comparable over time, providing an ongoing baseline of information to effectively assess learning enhancement.

\section{STEP 4: DEFINE PERFORMANCE RUBRICS}

The fourth step in developing an effective AOL process is to construct performance rubrics. Rubrics are a set of criteria used to evaluate student performance on the measures written in Step 2. A rubric provides clear guidelines on how to categorize student performance into one of three categories: exceeds, meets or fails to meet expectations. A well designed rubric should lead to consistency across evaluators; rubrics should be specific enough that different evaluators would classify student performance similarly. The style of a rubric will vary depending on the type of measure. If, for instance, assessment measures are in the form of multiple choice questions, a rubric may specify how many multiple choice questions students must answer correctly in order to exceed, meet or fail to meet 
expectations. If the assessment measure is instead in the form of an essay question the rubric will specify what the evaluator should look for in an answer in order to classify students into one of the three groups. Tables 6 and 7 provide examples of performance rubrics for multiple choice measures and essay question measures that could be used in our Principles of Microeconomics classes.

Table 6: Performance Rubric for Multiple Choice Questions

\begin{tabular}{|c|c|c|c|}
\hline & Exceeds Expectations & Meets Expectations & Fails to Meet Expectations \\
\hline LO1 & Correctly answers 4/4 & Correctly answers $3 / 4$ & Correctly answers less than $3 / 4$ \\
\hline LO2 & Correctly answers $4 / 4$ & Correctly answers $3 / 4$ & Correctly answers less than $3 / 4$ \\
\hline LO3 & Correctly answers $4 / 4$ & Correctly answers $3 / 4$ & Correctly answers less than $3 / 4$ \\
\hline LO4 & Correctly answers $4 / 4$ & Correctly answers $3 / 4$ & Correctly answers less than $3 / 4$ \\
\hline LO5 & Correctly answers $4 / 4$ & Correctly answers $3 / 4$ & Correctly answers less than $3 / 4$ \\
\hline & Exceeds Expectations & Meets Expectations & Fails to Meet Expectations \\
\hline LO1.1.1 & $\begin{array}{l}\text { Can draw, define and label a PPF } \\
\text { and use it to illustrate all of the } \\
\text { following: attainable, unattainable, } \\
\text { efficient and inefficient production } \\
\text { points }\end{array}$ & $\begin{array}{l}\text { Can draw, define and label a PPF } \\
\text { and use it to illustrate three of the } \\
\text { following: attainable, unattainable, } \\
\text { efficient and inefficient production } \\
\text { points }\end{array}$ & $\begin{array}{l}\text { Cannot draw, define and label a PPF } \\
\text { or use it to illustrate three of the } \\
\text { following: attainable, unattainable, } \\
\text { efficient and inefficient production } \\
\text { points }\end{array}$ \\
\hline
\end{tabular}

\section{STEP 5: EVALUATE THE DATA}

How do you determine whether a learning objective has been met? Are you satisfied if at least $2 / 3$ of students fall into the meets or exceeds expectations categories, or would you require at least 3/4? Targets may differ across learning objectives and even dimensions/sub-dimensions. Determining acceptable benchmarks can be difficult and is highly subjective. Moreover, evaluating data based on benchmarks alone creates an incentive for faculty to tinker with the level of difficulty of their assessment measures in order to hit certain targets.

In fact, when an assessment process is used for continual improvement a benchmark itself is less important than whether your numbers increase over time. And, if courses or programs are evaluated based on improvements over time rather than absolutes, faculty have less incentive to change the assessment measures in order to hit certain targets. Here again the need for pre-testing is apparent. Pre-testing controls for changes in student quality over time so that we can better assess the institutional impact of the course or program. Moreover, pre-testing controls for the difficulty of the assessment measures and therefore reduces the incentive faculty have to construct easier measures since the focus is on value-added.

Consider the results from our Principles of Microeconomics courses presented in Table 8. The first row reports the post-test percentages of students who answered at least three out of four multiple-choice questions correctly for each of the five learning objectives and lists rankings based on these percentages. Figure 1 depicts these results and demonstrates that the largest percentage of students met expectations for LO1 and the smallest percentage met expectations for LO4. However, when we look at the second row of Table 8 we see that baseline pre-test performance is dramatically different across LO's. This suggests that some LO's had multiple-choice questions that were either easier to guess or were based on concepts that students had some intuitive familiarity with prior to taking the course. The third row of Table 8 compares the pre-test percentages to the post-test percentages. Figure 2 illustrates this comparison and shows that the greatest value-added was made for LO3 and the least for $\mathrm{LO} 2$.

A simple evaluation of Figures 1 and 2 together reveals that absolute performance is not a good measure of value-added. Although absolute performance is highest for LO1, value-added is greatest for LO3. Additionally, while LO2's absolute performance is second highest, its value-added is lowest. These results demonstrate that having data on both absolute performance and pre-post gains gives a much clearer picture of learning. This is especially important when using the assessment process to "close the loop" as will be discussed next in Step 6. 


\begin{tabular}{|c|c|c|c|c|c|}
\hline & LO1 & LO2 & LO3 & LO4 & LO5 \\
\hline \multicolumn{6}{|l|}{ POST-TEST } \\
\hline \% Meets or Exceeds Expectations & $65.83 \%$ & $54.17 \%$ & $46.25 \%$ & $45.83 \%$ & $49.58 \%$ \\
\hline Rank (based on absolute \%) & 1 & 2 & 4 & 5 & 3 \\
\hline \multicolumn{6}{|l|}{ PRE-TEST } \\
\hline \% Meets or Exceeds Expectations & $14.17 \%$ & $26.67 \%$ & $6.25 \%$ & $12.08 \%$ & $7.92 \%$ \\
\hline Rank & 2 & 1 & 5 & 3 & 4 \\
\hline \multicolumn{6}{|l|}{ PRE-POST } \\
\hline Percentage Points Gained & 51.66 & 27.5 & 40 & 33.75 & 41.66 \\
\hline Percentage Gain & $365 \%$ & $103 \%$ & $640 \%$ & $279 \%$ & $526 \%$ \\
\hline Rank (based on \% gain) & 3 & 5 & 1 & 4 & 2 \\
\hline
\end{tabular}

$\mathrm{N}=240$
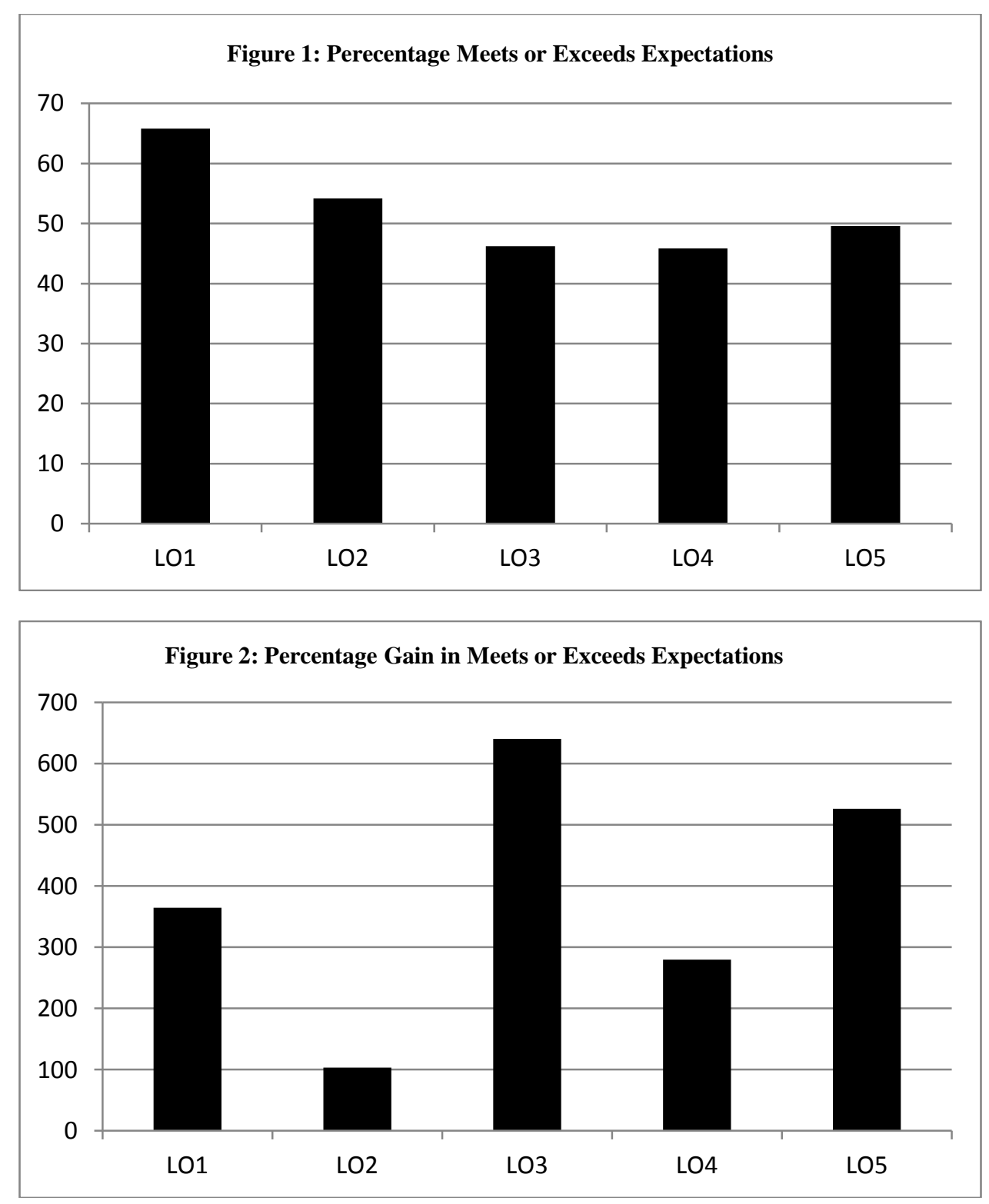


\section{STEP 6: CLOSE THE LOOP}

The value of assessment of learning is not just the determination of whether learning objectives are met but importantly the use of this information to develop a process for continual improvement. In this final step, you will develop and implement a plan for improvement if a learning objective is not met and then re-asses the learning objective to evaluate the impact of your plan. This critical step of your assessment of learning process closes the loop

If your assessment data reveals that a learning objective is not being met, develop an action plan of content, pedagogical or curricular changes designed to improve performance. Sub-dimensions can be helpful in this step. Because they are narrower than learning objectives, they will better reveal where specifically a learning objective is not being met and help you formulate a plan for improvement tailored to the specific skill of the sub-dimension. Sometimes an action plan will focus on the course you are assessing. However, it is possible that the changes need to occur in another course. Once more, this is a benefit of pre-testing. Since we can measure what students know at the beginning of a course or program, we can get a sense for whether changes need to be made before a course/program in order to address any deficiencies.

Lastly and importantly, evaluate the impact of your changes in the next assessment loop. Determine whether your action plan improved performance in meeting your learning objective. If it did, continue to incorporate the change. Are you still not meeting expectations? If so, develop another action plan to make improvements. Remember that assessment in an ongoing process. We as educators should be regularly evaluating the extent to which we are meeting our goals and making changes as necessary to improve.

\section{CONCLUSION}

In this paper we outlined a methodology for the development of a simple and effective assessment protocol that provides meaningful results that can be used to evaluate and enhance learning over time. Our six step process begins by asking the question, "What do we want our students to learn?" and then illustrates how to develop learning objectives, assessment measures, and rubrics with the ultimate goals of determining whether our students are learning what we want them to learn, finding out where we can improve, and evaluating pedagogical or curricular changes designed to improve performance.

We also discuss the benefits of pre-testing to measure value-added as opposed to absolute performance measures. We believe the importance of implementing a consistent and repeated pre-post testing procedure cannot be emphasized enough. Meaningful relative comparisons are critical to accurately measuring the outcome of changes in pedagogy over time. Without such a protocol it will be nearly impossible to effectively demonstrate the successful "loop-closing" cycles of continuous improvement that assessment agencies increasingly require.

We understand the resistance to assessment of learning in higher education. However, assessment of learning is here to stay. Instead of resisting this process, we believe it is important to embrace it and change the view of assessment as a bureaucratic requirement to a valuable pedagogical tool.

\section{AUTHOR INFORMATION}

Dr. Michelle Sheran is a Senior Lecturer in the Department of Economics, University of North Carolina at Greensboro, NC, USA. Her research interests include household economics, foster care, assessment of learning, and economic education. E-mail: mesheran@uncg.edu

Dr. Jeffrey Sarbaum is a Senior Lecturer in the Department of Economics, University of North Carolina at Greensboro, NC, USA. His research interests include multimedia pedagogy, online teaching effectiveness, and assessment of learning. E-mail: jksarbau@ uncg.edu (Corresponding author) 


\section{REFERENCES}

1. Allen, M. J. (2004). Assessing Academic Programs in Higher Education. Bolton, MA: Anker Publishing Company.

2. American Association of State Colleges and Universities. (2006). Value-Added Assessment: Accountability's New Frontier. Perspectives. Retrieved from: http://www.aascu.org/uploadedFiles/AASCU/Content/Root/PolicyAndAdvocacy/PolicyPublications/06_pe rspectives\%281\%29.pdf

3. Caviglia-Harris, J. \& Hill, B. (2010). Assessment Plan and Design: A Model for Enhancing Instruction in Economics Courses. International Review of Economics Education, 9(1) 10-30.

4. Doran, H.C. \& Fleischman, S. (2005). Challenges of Value-Added Assessment. Assessment to Promote Learning, 63(3) 85-87.

5. Myers, S.C., Nelson, M.A. \& Stratton, R.W. (2009). Assessing An Economics Programme: Hansen Proficiencies, ePortfolio, and Undergraduate Research. International Review of Economics Education, 8(1) 87-105.

6. Myers, S.C., Nelson, M.A. \& Stratton, R.W. (2011). Assessment of the Undergraduate Economics Major: A National Survey. The Journal of Economic Education, 42(2) 195-199.

7. Walstad, W.B. (2001). Improving Assessment in University Economics. The Journal of Economics Education, 32(3) 281-294.

8. U.S. Department of Education. (2006). A Test of Leadership: Charting the Future of U.S. Higher Education. A Report of the Commission Appointed by Secretary of Education Margaret Spellings. Retrieved from: http://www2.ed.gov/about/bdscomm/list/hiedfuture/reports/final-report.pdf 